\title{
ALFRED DE MUSSET, Nouvelles
}

\section{Valentina Ponzetto}

\section{(2) OpenEdition \\ Journals}

Édition électronique

URL : https://journals.openedition.org/studifrancesi/22986

DOI : 10.4000/studifrancesi.22986

ISSN : 2421-5856

\section{Éditeur}

Rosenberg \& Sellier

\section{Édition imprimée}

Date de publication : 1 avril 2020

Pagination : 200

ISSN : 0039-2944

\section{Référence électronique}

Valentina Ponzetto, " ALFRed de musset, Nouvelles », Studi Francesi [En ligne], 190 (LXIV | I) | 2020, mis en ligne le 01 mai 2020, consulté le 03 août 2021. URL : http://journals.openedition.org/studifrancesi/ 22986 ; DOI : https://doi.org/10.4000/studifrancesi.22986

Ce document a été généré automatiquement le 3 août 2021.

\section{(c)}

Studi Francesi è distribuita con Licenza Creative Commons Attribuzione - Non commerciale - Non opere derivate 4.0 Internazionale. 


\title{
ALFRED DE MUSSET, Nouvelles
}

\author{
Valentina Ponzetto
}

\section{RÉFÉRENCE}

ALFRED DE MUSSET, Nouvelles, édition par G. Castagnès et Frank Lestringant, Paris, Classiques Garnier, 2019, 417 pp.

1 Dix ans après leur édition des Contes de Musset (Classiques Garnier, 2009, v. "Studi Francesi" 161, maggio-agosto 2010) Gilles Castagnès et Frank Lestringant nous offrent le pendant attendu avec l'édition critique du cycle des Nouvelles. Comme pour les Contes, le choix du texte de référence s'est porté sur la dernière édition parue du vivant de l'auteur: Charpentier, 1855, avec très peu d'interventions pour une modernisation de l'orthographe. Les variantes, peu nombreuses et publiées à la fin de chaque nouvelle, prennent en compte les quatre éditions de référence: les publications préoriginales dans la "Revue des deux mondes", du $1^{\mathrm{er}}$ aout 1837 au 15 février 1839, l'édition originale (Dumont, 1840), l'édition Charpentier 1841, et l'édition posthume dite «des Amis du poète» (1865-66), dont l'intérêt principal est représenté par les notes de Paul de Musset.

2 L'ordre de présentation des textes reprend également celui de l'édition Charpentier 1855: Les Deux Maîtresses, Emmeline, Le Fils du Titien, Frédéric et Bernerette, Croisilles, Margot. Ce choix, à notre avis discutable, ne reproduit pas l'ordre de composition et de parution dans la "Revue des deux mondes", qui conduisait par contre le lecteur d'Emmeline à Croisilles. Or l'adoption d'un ordre chronologique, comme par exemple dans l'édition de Sylvain Ledda (Flammarion, 2011) permettrait de mieux mesurer une évolution dans le cycle de ces six textes pourtant assez unitaires et rapprochés dans le temps. On y remarquerait plus nettement, par exemple, un effacement progressif des commentaires métatextuels et ironiques du narrateur, ou une fatigue d'écriture de plus en plus perceptible, qui culmine avec les raccourcis un peu cavaliers et la fin précipitée de Croisilles. Cette évolution est pourtant en partie liée aux circonstances de composition des Nouvelles, écrites sous la contrainte par besoin d'argent et terminées 
péniblement pour honorer le contrat éditorial passé avec Buloz, circonstances dûment évoquées par Gilles Castagnès dans la première partie de l'introduction.

Le problème de l'ordre des nouvelles choisi par Musset et reproduit dans ce volume est directement adressé dans la préface, accompagné du constat que les bouleversements «semblent méthodiques [...] les récits étant invertis deux par deux». "Aucune raison apparente ne venant justifier ces permutations», Gilles Castagnès avance l'hypothèse que Musset aurait voulu «brouiller les pistes» des identifications autobiographiques de ses amours (p. 16). L'hypothèse ne semble pourtant pas des plus solides. Premièrement, en effet, ces simples permutations ne changent pas le fonds des anecdotes et des rencontres qui ont pu inspirer l'écriture des nouvelles et qui sont scrupuleusement détaillées par Paul, l'omniprésent frère-éditeur. Ensuite et surtout - l'auteur ne l'oublie certes pas - ces souvenirs personnels sont très largement romancés, et les enjeux des nouvelles dépassent largement la donnée biographique.

Dans sa préface, Gilles Castagnès focalise son attention sur les personnages, les modes d'expression et l'esthétique du recueil, laissant des considérations plus spécifiques à l'une ou l'autre des nouvelles aux brèves introductions qui précèdent chaque texte. S'agissant de six histoires d'amour, l'analyse de l'expression des sentiments revêt la plus grande importance. Le critique constate la thématisation récurrente de la difficulté des personnages à dire leur amour, le recours à de nombreux signes nonverbaux pour pallier à cet indicible (langage des gestes, des regards, des fleurs, des objets, de la peinture, de la musique) et conclut que Musset met ici en place un véritable «laboratoire d'expression» montrant «l'expérimentation progressive (et parfois laborieuse) d'une mise en forme» (p.23) qui procède vers une distanciation progressive de la matière contée permettant enfin de dire l'ineffable. L'esthétique des nouvelles s'avère ainsi empreinte d'un certain classicisme déjà salué par les contemporains. L'écriture se caractérise par la rigueur et la linéarité du récit, l'économie de personnages, la simplicité des intrigues, à tel point que le critique applique à Emmeline le propos racinien de «faire quelque chose de rien» (p.124), et l'abandon des excès de lyrisme typiques d'une écriture romantique. La caractérisation des personnages, surtout des protagonistes masculins, plus âgés, désabusés, bourgeois et impuissants par rapport aux héros des années 1830-1834, fait pencher également pour une prise de distances d'avec l'esthétique romantique. Quant aux héroïnes, Gilles Castagnès propose de lire déjà chez elles des traits qui les apparentent aux personnages de Flaubert ou de Dickens, ouvrant les perspectives d'une forme de réalisme lato sensu.

5 Complètent le volume, outre une chronologie et une bibliographie très complète sur ce qui reste la partie la moins connue du corpus mussétien, des précieuses annexes: l'incipit écarté des Deux maîtresses, avec la savoureuse physiologie des dandys du boulevard de Gand; les contrats d'édition avec Buloz, accompagnés d'extraits de correspondance Musset-Buloz; le célèbre compte rendu de Balzac ("Revue parisienne", 25 septembre 1840); et un intéressant récapitulatif topographique, avec plans de Paris à la clé, des lieux parisiens convoqués non seulement dans les Nouvelles mais aussi dans les Contes. 